\title{
Terceira linguagem: discurso mercadológico com credibilidade construindo reputação nas organizações
}

Renato Rodrigues Martins

- Doutor e Mestre em Comunicação e Semiótica pela Pontifícia Universidade Católica de São Paulo (PUC-SP)

- Graduado em Comunicação Social com habilitação em Relações Públicas pela Universidade Estadual de Londrina (UEL)

- Professor da UEL e da Fundação Getúlio Vargas (FGV-Isae)

- Avaliador do MEC/Inep e consultor de empresas em comunicação e marketing

- renadri@gmail.com 
Resumo

O artigo apresenta proposta de Comunicação Organizacional e trata da mediação entre linguagem de marketing e linguagem institucional. A terceira linguagem expande as anteriores e integra atividades empresariais à credibilidade e reputação em um pensamento triádico. O comunicador obtém, assim, a integração de princípios éticos, culturais e de responsabilidade, construindo reputação e credibilidade sólidas.

PALAVRAS-CHAVE: COMUNICAÇÃO MERCADOLÓGICA • REPUTAÇÃO • LINGUAGEM • ÉTICA • RESPONSABILIDADE

\section{Abstract}

It presents proposal for organizational communication and addresses mediation between the marketing and institutional languages. The third language expands the previous ones and integrates business activities with the credibility and reputation of triad thinking. The communicator thus obtains integration of ethical, cultural and responsible principles, building solid reputation and credibility.

KEYWORDS: MARKETING COMMUNICATION • REPUTATION • LANGUAGE • ETHICS • RESPONSIBILITY

\section{Resumen}

Se presenta una propuesta de Comunicación Organizacional y se analiza la mediación entre el lenguaje de marketing y el lenguaje institucional. Se estudia todavía un tercer lenguaje, que expande los anteriores e integra las actividades empresariales a la credibilidad y la reputación, en un pensamiento triádico. El comunicador obtiene, así, la integración de los principios éticos, culturales y de responsabilidad, lo que le permite construir una reputación y una credibilidad sólidas.

PALABRAS CLAVE: COMUNICACIÓN MERCADOLÓGICA REPUTACIÓN • LENGUAJE • ÉTICA • RESPONSABILIDAD 
Este artigo analisa o ensino e a aplicação da linguagem da comunicação mercadolóEgica sob a ótica de uma nova forma de discurso comunicacional e estuda as abordagens éticas específicas chamadas persuasivas e de relacionamento. É um estudo voltado para a evolução da linguagem mercadológica de natureza institucional pela via da comunicação. A utilização de diferentes formas de discurso no ambiente de uma organização é compreendida de modo imperfeito e não se raciocina de forma triádica, com um campo de linguagem em que seja possível relativizar e determinar as características das linguagens que se contrapõem.

A alta oferta de produtos e o consumo desenfreado levam os profissionais de comunicação mercadológica à busca de soluções que permitam relacionar as estratégias a essa nova realidade. Há um confronto na Comunicação Organizacional e, conseqüentemente, no ensino, que requer uma mediação da qual o corpo teórico a ser obtido funcionará como elemento. A investigação é da natureza das teorias da Comunicação e da Administração e poderá receber contribuições na forma de métodos de análise que ainda não chegou a desenvolver em seu próprio corpo de conhecimentos.

A visão da comunicação no marketing inclina-se mais para os aspectos de persuasão e não pode anular outras formas de relacionamento com o consumidor. Uma nova forma de linguagem deve conter elementos sobre como se podem desenvolver posturas mais éticas, de responsabilidade, ao mesmo tempo em que não se descuida de fatores de natureza prática necessários ao sucesso comercial.

Profissionais devem orientar suas ações no sentido de interpretar as questões sociais e ecológicas e acrescentar aos consumidores uma preocupação socialmente responsável para angariar credibilidade e reputação. Devem estabelecer novos conteúdos e formas operacionais de produção e de promoção com segmentos para obter definições claras e coerentes sobre o equilíbrio entre a oferta e o consumo. Uma forma promocional, com um discurso mais racional e didático, deve influir no processo mercadológico, desde a produção e a distribuição de bens e serviços até a comunicação com os públicos da instituição.

O objeto de estudo da aqui chamada terceira linguagem é o diálogo entre duas formas comunicacionais para gerar uma terceira no interior da qual se possa relativizar ambas sem minimizar os efeitos para os quais são indispensáveis: o de marketing, vender satisfazendo as partes, e o institucional, o contato não-comercial com os públicos. Essas afirmações e preocupações são traduzidas nos objetivos dessa linguagem, em face da realidade atual em que estão o marketing e a comunicação mercadológica. Ela não deve e não pode ser excludente, pois medeia as outras linguagens. A proposição é que seja um tipo diferente, alternativo e integrado pelas outras formas tradicionais de linguagem.

A terceira linguagem gera credibilidade, pois estabelece um debate acerca da organização que trata seus clientes não como simples consumidores, mas na investidura de cidadãos conscientes, capazes de tomar decisões sobre o que se passa a sua volta, 
principalmente nas questões de consumo. Constrói reputação, pois harmoniza as necessidades humanas e os recursos empregados de forma racional e ecológica, equilibrando oferta e procura dos bens de consumo e deslocando o lugar único das outras duas linguagens para implantar no seu seio um discurso estável com a noção cultural mestiça e de ética da responsabilidade.

É nesse contexto que se pretende apresentar essa linguagem: orientar uma forma didática, criativa, crível e ética de discurso de marketing para criar reputação em uma cultura de consumo responsável.

\section{A terceira linguagem e a comunicação mercadológica}

Em um país emergente e com grandes mercados, os executivos de comunicação mercadológica enfrentam constantes desafios promocionais para os quais devem propor soluções que permitam criar educação no consumo com mais responsabilidade.

Há um confronto na promoção mercadológica, que requer mediação. O corpo teórico a ser obtido funcionará como elemento dessa mediação. É um estudo voltado para a evolução dos processos mercadológicos de natureza institucional pela via da promoção. As diferentes formas de discurso entre interlocutores inseridos no ambiente de uma organização - o consumidor aí incluído de modo preponderante - são compreendidas de modo imperfeito, incompleto ou distorcidas se não se raciocina de forma triádica, com um campo de linguagem em que seja possível relativizar e determinar as características das linguagens que se contrapõem.

Não permanece qualquer dúvida de que essa investigação é de natureza pedagógica das teorias da Comunicação. Nesse sentido, essa área - e também a Administração pode receber contribuições na forma de métodos de análise que ainda não chegou a desenvolver em seu próprio corpo de conhecimentos.

Atualmente, a visão da promoção no marketing inclina-se mais para os aspectos de persuasão e, conscientemente ou não, pode anular outras formas de relacionamento com o consumidor. A comunicação das organizações deve conter elementos sobre como se podem desenvolver posturas mais éticas, de responsabilidade, ao mesmo tempo em que não descuida de fatores de natureza prática necessários ao sucesso comercial.

Comunicadores devem orientar suas ações promocionais no sentido de interpretar as questões sociais e ecológicas e acrescentar aos consumidores uma preocupação socialmente responsável. Necessário se faz estabelecer novos conteúdos comunicacionais e formas operacionais de produção e de comunicação com segmentos específicos para obter definições claras e coerentes sobre o equilíbrio entre a oferta e o consumo. Um discurso mais racional e didático deve influir no processo de troca, desde a produção e a distribuição de bens e serviços até a comunicação com os públicos da instituição. 
Questões de responsabilidade ética nos relacionamentos institucionais que gerem credibilidade têm recebido grande destaque e atenção nos dias de hoje. Não se observa, no entanto, entre os atores voltados a objetos constituídos no ambiente institucional, a produção de enfoques tendo por base a idéia de mediação. Movimentos em favor da ética da responsabilidade, que valorizam a vida nos negócios, passam a representar a diferença no mundo empresarial, e o valor de uma marca é a resultante dessa nova percepção que o cliente desenvolve a respeito do comportamento social definido por uma empresa como postura estratégica para desenvolver seus negócios.

Ao transitar por questões de conquista de novos mercados, os profissionais dos setores de comunicação e de marketing necessitam, obrigatoriamente, adotar uma nova postura, uma visão de responsabilidade para com a sociedade, o que deve possibilitar um maior diálogo entre formas de linguagem que até então se excluíam mutuamente.

A proposta é alinhar esses dois mundos impenetráveis para compreender suas limitações e equilibrá-los. Um não deve necessariamente excluir o outro: o tido como confiável (que busca apenas os relacionamentos) e aquele do qual se diz sustentado apenas na produção de ilusões numa atmosfera enganosa. Essas afirmações e preocupações são traduzidas nos objetivos dessa linguagem, em face da realidade atual em que estão o marketing e a comunicação mercadológica.

Fortes (1999, p. 101) assim caracteriza o atual momento da comunicação institucional:

"Preocupações com o aprofundamento da consciência das pessoas nas questões macroambientais constituem, evidentemente, um comportamento politico por parte das Relações Públicas, fazendo disso uma meta prioritária na postura profissional atenta aos diversos cenários de atuação da empresa. [...] As instituições respeitam a multiplicidade de interesses que as cercam, e avançam para um posicionamento de Transmarketing quando reconhecem que os individuos e os grupos sofrem incessantemente as influências do ambiente externo."

O termo linguagem tem uma acepção adicional nessa proposta: a de funcionar como designação de um campo de trabalho. Em outras palavras, fala-se de linguagem de marketing e linguagem institucional de Relações Públicas. De inspiração predominantemente norte-americana, na primeira há um conjunto de autores discutindo formas de conquistar o consumidor; na segunda, com base nas ciências humanas, os textos fazem referência a modos de ver o consumidor na investidura de membro de um público com o qual a organização estabelece e tenta perpetuar relacionamentos.

O termo linguagem obriga a precisar melhor sua definição. Santaella (2002, p. 11) alerta para um equívoco de base quando se trata de diferenciar língua e linguagem. A autora ressalta que língua não é a única e exclusiva forma de linguagem que se pode produzir. O nosso estar-no-mundo, como indivíduos sociais que somos, é mediado por uma rede intrincada e plural de linguagem, imagens, gráficos, sinais, setas, números e luzes. 
Como base, a teoria dos gêneros de Mikhail Mikhailovitch Bakhtin (1895-1975) apresenta as características da terceira linguagem como discurso de uma organização e, ainda, na qualidade de produtora de sentido em um discurso. A teoria de Bakhtin elucida que os gêneros são mutáveis e dependem das mudanças sociais pelas quais um sujeito passa.

Bakhtin $(1977 ; 2000)$ propõe conceitos para os gêneros do discurso, suprindo a necessidade de se compreender o contexto dos discursos como fenômenos sociais, resultantes das ações mutáveis do homem. Os gêneros do discurso são parte de um repertório de formas disponíveis de linguagem e comunicação na sociedade em que se inserem. O ser humano, na sua intencionalidade e finalidades específicas para cada objetivo, utiliza a língua e a linguagem para realizar a retórica do seu discurso. Bakhtin deixa claro que, além da intencionalidade e da finalidade da utilização da língua, outros aspectos também contribuem para a formação de um discurso. Fatores culturais, valores e meio em que se vive, a classe social, o repertório e a experiência, a herança genética, entre outros, também diferenciam e compõem um discurso persuasório.

Os gêneros do discurso só existem se estiverem relacionados ao meio social em que se inserem e a língua deve ser entendida como resultado de um processo com razões históricas e sociais, uma maneira de interação social e verbal. Para ele, ao produzir uma enunciação, os participantes invocam uma linguagem social e esta configura o que a voz quer dizer. Esse processo de utilizar linguagens sociais acarreta o que o estudioso define como dialogia ou polifonia - um sistema no qual uma voz fala por meio de outra voz encontrada em uma linguagem social. A utilização desse sistema possibilita ao participante ser mais ou menos articulado com o uso da linguagem para alcançar seus objetivos, expandindo o seu repertório de gêneros discursivos.

O autor destaca o valor da palavra e, de maneira incisiva, chama a atenção para a sua importância na comunicação social - a palavra como uma unidade da linguagem e do sentido. A utilização da palavra implica a sua ideologia, por isso "pode preencher qualquer espécie de função ideológica: estética, científica, moral, religiosa” e a sua compreensão exige que se vá além do seu conteúdo ideológico, que se alcance o discurso do outro, realizado no universo simbólico de expressão individual. A ideologia de um discurso e a consciência individual dos interlocutores devem ser entendidas como elementos da linguagem que envolvem qualquer palavra, que são capazes de tornar compreensíveis as palavras em seu significado e em sua significação.

Para Bakhtin, é necessário levar em conta o meio onde se passa o diálogo - o entorno - e os discursos exteriores, os signos sociais que vão determinar e modelar a consciência individual dos participantes. Para facilitar as regras textuais, faz-se necessário conhecer os códigos (o sentido de expressão), adaptando a conduta e competência sígnica comunicacional. Para ele, texto - neste artigo tratado como linguagem - diz respeito à criação verbal nos seus aspectos culturais, não sendo apenas no resultado, mas também na representação textual que permite perceber o que está dentro e que determina a forma exterior do campo de visão. 
Nessa forma de reflexão, há espaço para discutir as posturas dos autores nas formas terminológicas de linguagem e discurso, ou seja, é possível falar com fidelidade do que pensam, mas essa reflexão mediadora terá diante de si o desafio de criar respostas e soluções como práticas de linguagem às distorções próprias das linguagens mencionadas. Como se está tratando indistintamente - por questões conceituais e não relevantes ao texto - os termos linguagem e discurso, discutindo sobre suas formas, passa-se a adotar, para efeito de combinar expressões, o termo terceira linguagem.

O discurso persuasivo dos meios de comunicação mercadológicos apresenta a publicidade como arma de conquista de espaço na mente do consumidor, representando maior participação no share de mercado. Barbosa (1997) define com clareza o conjunto de questões envolvidas nessa discussão:

"Não se trata de designar a articulação publicitária como fonte de todos os males das sociedades capitalistas... Para tanto são utilizados numerosos recursos simbólicos que assumem, pelo implicito dos discursos, os aspectos lúdicos (positivos e/ ou negativos), pois não se trata apenas uma ação de representar, mas que se inscreve num conjunto social e bem-definido. É um aparelho ideológico que difunde um poder especifico."

O ponto de debate dessa linguagem é centrado na idéia de que a comunicação mercadológica, por si só, já deve conter uma visão conseqüencialista, ética e responsável. Essa forma de linguagem medeia as outras linguagens, pois é integrada pelas outras formas tradicionais de linguagem: a de marketing, a qual busca aumento de participação no mercado, e a linguagem institucional que apresenta e divulga a instituição a fim de criar um conceito forte e favorável para a organização.

\section{A responsabilidade na comunicação com o consumidor}

Muito se tem estudado sobre o consumidor e suas formas de comportamento ou de consumo, uma vez que, colocado como alvo, passa a ser necessário compreendê-lo. Há diversos ângulos em que é focado, mas o que interessará é o ponto de vista de consumidor de produtos e produtor de discursos. O homem reage diante dos estímulos externos, de acordo com sua formação biológica e seu comportamento, e o consumidor busca, nos seus atos, elementos de segurança, prestígio, status e poder na relação entre ele e o grupo. Trata-se de um assunto de linguagem, na medida em que é a linguagem o que organiza, desorganiza, harmoniza ou provoca desencontros que produzem maior ou menor sucesso desses estímulos.

O consumidor atual médio não leva em conta, entre outros aspectos, o custo ambiental da satisfação do seu desejo. As instituições têm compromissos financeiros a cumprir e, muitas vezes, por esse motivo, atropelam seus comprometimentos sociais. Propor novos meios e mensagens com novas formas discursivas, criar vínculos maiores com a instituição à qual o consumidor está ligado, desenvolver uma forma de equilibrar essência e aparência seria elevar o cliente à categoria superior de indivíduo.

Pichon-Rivière (1998) analisa o consumidor do ponto de vista do cotidiano, lembran- 
do que os meios publicitários invadem sua mente com marcas, slogans e imagens, buscando sempre a sua sedução. Cada objeto da comunicação publicitária se converte numa isca para uma possível tentação. O autor chama de "conduta consumidora" a forma de comportamento de caráter psicológico e, acima de tudo, social que pode ser moldada pelo grupo a que o sujeito pertence, ou deseja pertencer.

Um consumidor, ao adquirir, está constantemente tomando uma decisão, assumindo uma posição que pode merecer uma classificação ética, visto que adota, ou não, o discurso de certos produtos e marcas. Existe uma identificação entre o produto e o seu detentor, e o inter-relacionamento do eu e do meu torna-se inevitável. É nesse momento que o sentimento de posse, que o consumidor tanto deseja e busca, será satisfeito ou não. A posse de bens de consumo lhe dá segurança, aumenta a sua autoestima e, principalmente, satisfaz suas necessidades básicas. Comprar, então, significa estabelecer um vínculo entre o objeto comprado e o seu detentor, escapar da solidão, aderir a um grupo, adquirir um lugar no mundo.

As mercadorias são compradas pelas imagens que possam produzir e veicular na vista e na vida do consumidor, e não por seus benefícios reais ou valor intrínseco de uso. As necessidades tanto vêm pelo estômago quanto pelos olhos. Ou, numa outra forma de caracterização: a mente conta para a boca o que é mais apetitoso. Não é o carro que o consumidor deseja adquirir para substituir, por ser melhor, aquele que já possui no momento; é a mensagem que a mente transmite de que aquela substituição é indispensável. Trata-se da satisfação de voltar a adquirir, consumir. Se esse tipo de disposição acontece sempre a intervalos curtos, maior o sucesso comercial da empresa produtora. $O$ cliente não enxerga esse comprometimento mente-enviando-para-aboca e não se considera refém desse mecanismo.

O entendimento do consumidor é aprofundado no que Pichon-Rivière lembra como "atitude aquisitiva", que, segundo os psicólogos americanos, é uma atitude entendida como ponto de conexão entre o consumidor e seu meio, é uma posição que ele adota mediante um produto, idéia ou uma situação concreta; é uma tomada de posição frente aos objetos de consumo.

Outra forma de comportamento do consumidor é a definida como do "autodirigido", que é aquele consumidor mais consciente e que tem filtros. Em outras palavras, que tem a capacidade de não ser submisso aos incessantes estímulos da comunicação persuasiva. A comunicação para esse consumidor "autodirigido" merece maior estudo, aproveitando o fato de que este está consciente dos prejuízos que seus atos podem causar se não forem observadas regras básicas para uma conduta consumidora mais responsável. São questões éticas e ecológicas que carecem de estudo mais aprofundado.

Para o filósofo alemão Hans Jonas (1903-1993), existe uma nova ética, uma forma de pensar no futuro que exige responsabilidade nos atos do ser humano. Seria uma ética que, em primeiro lugar, valorize a vida, não somente a vida humana, mas todas elas, na qual o bem é a razão de todo o mundo, pois os preceitos éticos da visão antropocêntrica não mais são suficientes ao ser humano. Hoje é necessário um novo pensar e 
agir. A compulsão desenfreada, indiferente às conseqüências, representa uma grande ausência de responsabilidade, traduzida na falta de cuidado com o ambiente em que se vive. Jonas investiu toda a sua vida para a criação de uma ideologia ecológica, cujos principais pressupostos devem ser um pensar ético da contemporaneidade. Não se pode pensar a cultura contemporânea, essa que os meios de massa expressam, sem pensar os princípios éticos de uma ideologia ecológica responsável.

Os avanços tecnológicos, se mal administrados, podem criar conseqüências que afetem a vida humana e todo o planeta, apesar de permitirem as grandes conquistas deste século, no campo das ciências. "A liberdade que a ciência adquiriu ocupa posição única na humanidade, não limitando os outros direitos" (JONAS, 1995, p. 137). É fundamental perceber que existe aí uma contradição, porque os avanços científicos alcançados graças a essa liberdade significam uma posição de poder e de posse, enquanto que a pretensão de incondicionalidade da liberdade da investigação tem de se restringir à atividade de investigar o conhecimento, diferentemente da esfera da ação (JONAS, 1995).

Assim, Jonas entende que deve haver responsabilidade na ação e que a liberdade exagerada não impõe as necessárias responsabilidades no agir, levando o ser humano às desconsiderações sociais. O grande paradoxo é o fato de que o homem controla a natureza por meio de uma técnica que ele não controla mais. Para ele, a liberdade da ciência é um direito supremo, e deve estar livre de toda e qualquer barreira.

A responsabilidade seria, então, uma preocupação com o futuro, próprio e do próximo, que poderia representar a garantia da existência humana, de tudo que está ao seu alcance. Se existe o poder sobre a natureza, também se devem adotar responsabilidades sobre ela. Um novo agir representaria uma mudança de comportamentos e atitudes; seria buscar o próprio bem, mas, acima de tudo, o bem coletivo.

Por outro lado, pela noção de público (o consumidor com um papel expandido) entende-se não somente um grupo de pessoas que essa ou aquela instituição tem como objetivo. Nem tampouco é aquele grupo de pessoas a que se refere constantemente a mídia, os espectadores em um espetáculo ou ainda o povo em geral. Para se ter um público, ou um público específico, primeiramente é necessário que a empresa trate-o, ou deseje tratá-lo, como público. Todo público tem um motivo polarizador que o define e converte em membro de um determinado público. Os meios de comunicação, principalmente os publicitários, invadem as pessoas diariamente com uma enorme quantidade de informações, imagens, slogans e marcas que irão afetá-lo diariamente e massificá-lo.

Público de uma organização é um grupo de pessoas de interesse específico, com características preestabelecidas e com um objetivo definido, com a oportunidade e a capacidade de receber informações sobre um determinado assunto e que tenham poder de partilhar essas informações, ou seja, de discutir sobre um determinado assunto, tornando-o público. Conforme Andrade (1993, p. 17), deve-se entender por público:

"Pessoas ou grupo de pessoas organizadas, sem dependência de contatos fisicos, encarando uma controvérsia, com idéias divididas quanto à solução ou medidas a serem 
tomadas frente a ela; com oportunidade para discuti-la, acompanhando e participando do debate por intermédio dos veículos de comunicação ou da interação pessoal."

Portanto, o que se chama de terceira linguagem estabelece um campo de mediação em que se expande o debate acerca da comunicação da organização que trata seus clientes não somente como simples consumidores de seus produtos ou serviços, mas também na investidura de um cidadão pensante e consciente - o público - capaz de tomar decisões sobre tudo que se passa a sua volta, inclusive, e principalmente, se as questões de consumo responsável forem atingidas. Assim, poderá ser observado o surgimento de um contexto mais adequado às necessidades humanas, e os recursos poderiam ser empregados de forma racional e ecológica, equilibrando inclusive a oferta e a procura dos bens de consumo.

Outro filósofo alemão, Haug (apud MARCONDES FILHO, 1988, p. 35), levantando a questão da abordagem estética no estudo do consumidor, considera:

“... a tecnocracia dos sentidos um fator de consumo, já que impera na produção do ilusório, do imaginário. A estética da mercadoria atua como sensualidade, as mercadorias expostas na vitrine mostram-se para seus possiveis compradores com olhares sensuais, provocativos, sugerindo ao comprador que as leve."

O entendimento de consumidor atual está muito próximo do consumista, aquele que deseja e consome sem ao menos levar em conta, entre outros, os custos - principalmente o ambiental - da satisfação do seu desejo. As instituições têm compromissos mercadológicos e financeiros a cumprir e muitas vezes atropelam seus comprometimentos e responsabilidades sociais. Propor posturas mais responsáveis com novas mídias e mensagens, criar vínculos maiores com a instituição à qual o consumidor está ligado, desenvolver uma forma de equilibrar essência e aparência seria elevar o cliente à categoria de indivíduo, a verdadeira função da terceira linguagem.

\section{Um profissional de comunicação ético e mestiço}

Compra, contrato, confiança, desconfiança, promessas, credibilidade, sinceridade, verdade, equilíbrio, responsabilidade no consumo e outros termos ditos como parte integrante da ética comercial não são percebidos como rotineiros no dia-a-dia da comunicação de marketing, mas necessitam cada vez mais ser incorporados ao vasto vocabulário profissional dessa atividade mercantilista. Para que gerem reputação, tais enunciados carecem fazer parte de uma forma de comunicação mais crível, sintonizada com os anseios da clientela, bem informada e cada vez mais consciente de seus direitos e deveres de consumidor.

Hoje em dia os produtos estão cada vez mais semelhantes e o cliente tem várias opções de compra de produtos que só se diferenciam pela sua comunicação. O diferencial competitivo passou do plano físico para o plano perceptual. E quando ele pode optar por consumir com equilíbrio e mais responsabilidade, certamente irá comprar da 
empresa que se comporta com responsabilidade e que tenha reputação perante seus públicos. É exatamente aí que está a barreira entre o simples consumidor e o relacionamento entre empresa cidadã com seus públicos.

A comunicação mercadológica deve ter um enfoque baseado em relacionamentos dos públicos organizacionais fundamentais: empregados e seus familiares, consumidores, acionistas, imprensa, autoridades, fornecedores, distribuidores, comunidades e as instituições não-governamentais. Além desses públicos, os profissionais de comunicação e de marketing devem zelar, ainda, pelas marcas de produtos existentes nas empresas e manejar outras demandas além daquelas ligadas ao marketing e à comunicação, pois são fundamentais para o sucesso de suas empresas.

Cabe, nesse contexto, utilizar a terceira linguagem, construída com base nas contribuições teóricas aqui apresentadas, como uma forma comunicacional que irá trafegar por diferentes áreas administrativas, auxiliando a organização a atingir seus objetivos, sejam mercadológicos ou mesmo de cidadania corporativa.

O profissional deverá saber mediar diferentes linguagens, estudar os princípios que fundamentam aspectos culturais dos públicos e das organizações em que se inserem e deve ter características do hibridismo cultural que se apresenta. No Brasil, as organizações e os profissionais convivem com essa mestiçagem. O uso do termo pode produzir uma metáfora de bom poder explicativo: o povo brasileiro está apto a transitar pelas diferentes culturas e linguagens pela sua formação - o brasileiro é mestiço por natureza e transita por culturas diversificadas que formam as personalidades física e jurídica desse país continental. Assim, a terceira linguagem só fará sentido se conseguir mediar outras formas de linguagem, como que a criar uma alternativa à hegemonia da linguagem de marketing e da linguagem dita institucional, a de Relações Públicas, que se baseia em relacionamentos. Deverá retirar o topos - lugar único das outras duas linguagens - para implantar no seu seio uma linguagem estável, com a noção cultural mestiça e de ética da responsabilidade.

Nesse contexto, Paulo Nassar discute a importância do profissional de comunicação e de marketing ter um amplo repertório, com uma visão ampliada das necessidades da empresa e das possibilidades da comunicação mercadológica. O autor emprega o termo mestiçagem, enfatizando que o profissional deve ser mestiço do ponto de vista de conhecimentos e deve ter a capacidade de transitar por diferentes territórios culturais, não apenas os comunicacionais. E completa (2004):

"Questões que extrapolam, pela abrangência e impacto, as competências dos comunicadores tradicionais. Carecem, para serem bem resolvidas, de profissionais e equipes intelectualmente mestiças, com conhecimento e experiências além da comunicação, em campos como as Ciências Sociais, Administração, Psicologia, Antropologia, História, Direito, Arquitetura, entre outros. É essa mestiçagem profissional que garante o bom futuro da comunicação de uma organização." 


\section{0 caráter pedagógico da terceira linguagem}

Como contribuição aos profissionais do setor - e ao consumidor dos países emergentes -, a terceira linguagem pretende apresentar-se como uma nova forma discursiva, uma linguagem intermediária que não exclua as duas outras, mas possibilite uma reflexão de como ela deve inserir-se no contexto atual do terceiro setor e sua forma de comunicação. Como principais características da chamada terceira linguagem, podem-se citar algumas: apresentar ousadia e modernidade; tratar a comunicação como uma ferramenta de relacionamento que deverá criar vínculos com o público, dosando as características persuasivas com a institucional; procurar tratar o consumidor como um ser mais conscientizado dos aspectos sociais, culturais, éticos e ambientais e as implicações de sua compulsão ao consumo; não fantasiar os problemas das empresas e do cliente, abordando-o de frente e propondo soluções com participação conjunta; oferecer aos consumidores argumentos racionais para que eles consumam o produto; oferecer as informações técnicas e científicas, se for o caso, sobre o produto ou o assunto em questão; abrir novos meios que permitam ao cliente sua efetiva participação nas decisões da empresa, fundamentando a ética da responsabilidade.

Em síntese, é uma nova forma de discurso e de comportamento profissional, cuja implementação resultará em equilíbrio entre a oferta - mais racional de bens e serviços - e o consumo responsável, por intermédio de uma comunicação mercadológica efetiva com os consumidores, para se obterem resultados efetivos em relação à produção e ao consumo, uma melhoria dos relacionamentos nos negócios e da sociedade em que se inserem.

Nesse processo, fica evidente que ações consumeristas e inconseqüentes - de ambas as partes - provocam desencontros de atitudes e incompatibilidade preservacionista no sistema mercadológico. Grosso modo, a comunicação e o marketing devem criar dispositivos que possam gerar educação pública, incremento de informações para desenvolver massa crítica nos consumidores, valorização da cultura, responsabilidade no consumo, análise na relação de custos e benefícios do consumo e uma melhoria constante da sociedade.

A terceira linguagem propõe, sob os preceitos da ética, que somos responsáveis por tudo e por todos e temos o poder de decidir os destinos coletivos. Se há o poder, há também a conseqüente responsabilidade e obrigação para com o futuro, pois não se pode comprometê-lo. Como contribuição aos estudantes de comunicação e de marketing, a terceira linguagem apresentou valores que não excluem os princípios das duas outras. Tais princípios foram elaborados com a finalidade de instrumentalizar uma reflexão para uso na gestão da comunicação mercadológica em seu papel de inclusão social e justiça, voltada para a melhoria das relações comerciais e da sociedade como um todo.

A terceira linguagem deve ter o cuidado para não mascarar os verdadeiros motivos dos outros discursos das organizações, tampouco perder suas características didáticopedagógicas e a necessária capacidade de crítica social. Há uma multiplicidade de 
elementos a examinar no contraste entre o relacionamento puramente comercial e o institucional. Por entender ser possível a convergência entre esses dois tipos de expressão, pois eles não se excluem, a terceira linguagem requer do profissional a capacidade de transitar. Ele deve partir do desafio do confronto entre dois universos discursivos e efetuar uma enunciação capaz de colocá-los em sintonia para ultrapassar suas limitações e barreiras.

Profissionais de comunicação devem orientar suas ações promocionais no sentido de interpretar as questões sociais, éticas, culturais e ecológicas e acrescentar, aos consumidores, uma postura socialmente responsável. Para tanto, necessitam de bases a serem encontradas fora de seu campo de estudos habitual. O profissional deve seguir promovendo a formação de públicos e orientando a comunicação institucional. Dele é também esperado o mesmo nível de preocupação e envolvimento. Embora seja possível encontrar um grande montante de recursos conceituais nessa área, também não se pode eximir do fato de que é necessário transitar por outras áreas.

Ensinar a pensar e estimular a capacidade de discernir: eis o desafio de quem cria, forma e educa. O esforço nesse sentido, qualquer que seja sua natureza, deve ser permanente, e o fato de trabalhar com discursos, sobretudo aqueles que podem promover a melhora da vida das pessoas, é mais do que um objetivo: é uma motivação.

\section{Referências}

ANDRADE, Cândido Teobaldo de Souza. Para entender relações públicas. 4 ed. São Paulo: Loyola, 1993.

BAKHTIN, Mikhail. Marxismo e filosofia da linguagem. São Paulo: Hucitec, 1977. . Estética da criação verbal. São Paulo: Martins Fontes, 2000.

BARBOSA, I. S. Contribuições para uma semântica contexto-situacional na área publicitária. Dissertação (Mestrado em Comunicação) - Escola de Comunicações e Artes. São Paulo: Universidade de São Paulo, 1977.

FORTES, Waldyr Gutierrez. Transmarketing: estratégias avançadas de relações públicas no campo do marketing. São Paulo: Summus, 1999.

HAUG, W. F. A crítica da estética da mercadoria. In: MARCONDES, Filho, C. (org.) A linguagem da sedução. São Paulo: Perspectiva, 1988.

JONAS, Hans. El principio de responsabilidad: ensayo de una ética para la civilización tecnológica. Barcelona: Herder, 1995.

KOTLER, Philip. Administração de marketing. 10 ed. São Paulo: Prentice Hall, 2001.

LEVITT, Theodore. A moralidade da publicidade. São Paulo: Biblioteca Harvard de Administração de Empresas, IV, v. 9, 1985.

MORIN, Edgar. A cabeça bem feita. Rio de Janeiro: Berthand-Brasil, 2000.

NASSAR, Paulo. Viva a mestiçagem. Revista Meio \& Mensagem - especial Comunicação Corporativa - 8 nov. de 2004.

PICHON-RIVIÈRE, Enrique; QUIROGA, Ana P. Psicologia da vida cotidiana. São Paulo: Martins Fontes, 1998.

PINHO, J. B. Comunicação em marketing: princípios da comunicação mercadológica. 2 ed. Campinas: Papirus, 1991. . Propaganda institucional: usos e funções da propaganda em relações públicas. São Paulo: Summus, 1990.

RIES, Al. As leis vencedoras do Marketing. Fita de vídeo produzida por HSM Management. 50 min. Legendado. 1998. SANTAELLA, Lúcia. Semiótica aplicada. São Paulo: Pioneira Thomson Learning, 2002.

SANT'ANNA, Armando. Propaganda: teoria, técnica e prática. 7 ed. rev. São Paulo: Thomson, Pioneira, 1998. 